This article was downloaded by: [Uppsala University Library]

On: 23 January 2009

Access details: Access Details: [subscription number 907960494]

Publisher Taylor \& Francis

Informa Ltd Registered in England and Wales Registered Number: 1072954 Registered office: Mortimer House, 37-41 Mortimer Street, London W1T 3JH, UK

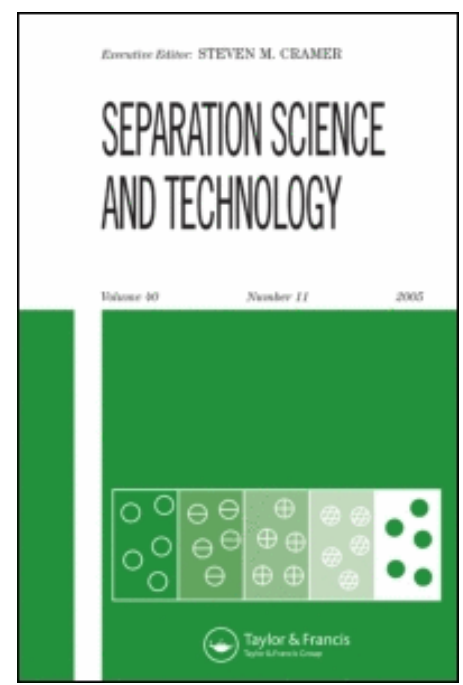

\title{
Separation Science and Technology
}

Publication details, including instructions for authors and subscription information:

http://www.informaworld.com/smpp/title content=t713708471

\section{Purification of Recombinant Human Serum Albumin (rHSA) Produced by Genetically Modified Pichia Pastoris \\ M. Belew ab; Li; Mei Yan; Zhang bc; Wei bc; K. Caldwell b}

${ }^{a}$ GE Heathcare Bio-sciences, Björkgatan, Uppsala, Sweden ${ }^{\text {b }}$ Center for Surface Biotechnology, University of Uppsala, Biomedical Center, Uppsala, Sweden ${ }^{\circ}$ North China Pharmaceutical Group Corp., Shijiazhuang, Hebei Province, China

Online Publication Date: 01 August 2008

To cite this Article Belew, M., Li, Yan, Mei, Zhang, Wei and Caldwell, K.(2008)'Purification of Recombinant Human Serum Albumin (rHSA) Produced by Genetically Modified Pichia Pastoris',Separation Science and Technology,43:11,3134 - 3153

To link to this Article: DOI: $10.1080 / 01496390802221857$

URL: http://dx.doi.org/10.1080/01496390802221857

\section{PLEASE SCROLL DOWN FOR ARTICLE}

Full terms and conditions of use: http://www.informaworld.com/terms-and-conditions-of-access.pdf

This article may be used for research, teaching and private study purposes. Any substantial or systematic reproduction, re-distribution, re-selling, loan or sub-licensing, systematic supply or distribution in any form to anyone is expressly forbidden.

The publisher does not give any warranty express or implied or make any representation that the contents will be complete or accurate or up to date. The accuracy of any instructions, formulae and drug doses should be independently verified with primary sources. The publisher shall not be liable for any loss, actions, claims, proceedings, demand or costs or damages whatsoever or howsoever caused arising directly or indirectly in connection with or arising out of the use of this material. 


\title{
Purification of Recombinant Human Serum Albumin (rHSA) Produced by Genetically Modified Pichia Pastoris
}

\author{
M. Belew, ${ }^{1,2}$ Li, Mei Yan, Zhang, ${ }^{2,3}$ Wei, $^{2,3}$ and K. Caldwell ${ }^{2}$ \\ ${ }^{1}$ GE Heathcare Bio-sciences, Björkgatan, Uppsala, Sweden \\ ${ }^{2}$ Center for Surface Biotechnology, University of Uppsala, \\ Biomedical Center, Uppsala, Sweden \\ ${ }^{3}$ North China Pharmaceutical Group Corp., Shijiazhuang, \\ Hebei Province, China
}

\begin{abstract}
Recombinant human serum albumin (rHSA) was produced by genetically transformed Pichia pastoris yeast. The cell-culture supernatant (CCS) contained $8-12 \mathrm{~g} / 1$ rHSA that was purified in a three-step procedure involving (1) a capture step using the newly developed cation exchanger Capto ${ }^{\mathrm{TM}}$ MMC; (2) an intermediate step using Phenyl Sepharose ${ }^{\mathrm{TM}}$ and, (3) a polishing step using Aminobutyl Sepharose ${ }^{\mathrm{TM}} 6$ FF. The total recovery was $25-35 \%$ and the product fulfils the purity criteria of the European Pharmacopeia.

Purified rHSA and plasma-derived HSA were essentially identical judging by SDS- or native-PAGE, and the pigment level (expressed as $\mathrm{A}_{350} / \mathrm{A}_{280}$ ) in the rHSA was 0.03 or less and was strongly dependent on the quality of the CCS. Dimers and polymers in the final product were less than that found in purified plasma-derived HSA. The molar mass of the purified rHSA, as well as of its natural counterpart, is 67000 Daltons by MALDI-ToF mass spectrometry, while the iso-electric points of both recombinant and natural HSA ranged between $\mathrm{pH}$ 5.42-5.55 when determined in $8 \mathrm{M}$ urea. The stability profiles of both proteins after heat treatment were identical as determined by differential scanning calorimetry (DSC). The results obtained here suggest the purified rHSA to be a homogeneous protein identical to its natural counterpart.
\end{abstract}

Keywords: Fermentation, HSA, human serum albumin, P. pastoris, purification, rHSA, SDS-PAGE

Received 19 December 2007; accepted 2 May 2008.

Address correspondence to K. Caldwell, Center for Surface Biotechnology, University of Uppsala, Biomedical Centre, P.O. Box 577, SE-75123, Uppsala, Sweden. E-mail: karin.caldwell@ytbioteknik.uu.sc. 


\section{INTRODUCTION}

Human serum albumin (HSA) is by far the most abundant protein in the circulatory system of human blood accounting for at least $50 \%$ of the proteins in human blood plasma. This corresponds to a concentration of approximately $35-40 \mathrm{~g} \mathrm{HSA} / \mathrm{L}$ of blood. HSA has a variety of physiological functions the most important of which are the following:

1. maintenance of the normal osmotic pressure of blood (homeostasis) $(1,2)$

2. transport of a variety of substances such as vitamins and hormones (1), fatty acids, bilirubins, various drugs, etc. (3) and several divalent metal ions such as $\mathrm{Zn}, \mathrm{Co}$, (4) and $\mathrm{Cu}(5,6)$, etc. It has 3 binding domains, each of which is specific for distinct classes of organic molecules such as BILIRUBIN (representing pigments), WARFARIN (representing drugs) and LAURIC ACID (representing fatty acids);

3 . it is a source of easily available reserve protein, e.g. in hypoproteinemia, starvation, etc.

HSA is frequently used in biochemical research, e.g. as a "protein diluent" (7), to coat hydrophobic surfaces, or to stabilize dilute vaccine preparations, etc. Indeed, both HSA and its bovine analog BSA are among the most characterized of proteins partly because of their abundance and availability in large quantities. HSA is a single-chain monomeric protein with a MW of approx. 67000 dalton (some 3-6\% can be in a dimeric form). It has an iso-electric point of approx. 4.7-5.5 (native form), and approx. 5.9-6.0 (in 8 $\mathrm{M}$ urea), and it is composed of 585 amino acid residues of which approximately 200 are charged groups $(1,8)$. It contains: 35 half-cystines of which 17 are in disulphide form; 17-18 His residues (one of the few proteins that contains so much His); 156 residues of hydrophobic amino acids (Val, Leu, Ile, Phe, and Tyr) and 1 residue of Trp.

Traditionally, HSA has been purified from pooled human blood obtained from donors. Various separation methods have been used for its purification (e.g. ammonium sulphate fractionation, precipitation with cold ethanol or high molecular weight polymers, and a variety of chromatographic methods). Of these, only two proved to be suitable for industrial-scale purification, viz. Cohn's cold ethanol fractionation method (9), and column chromatography $(10,11)$. However, due to the high cost of blood and the increasing risks for viral infections (e.g. HIV, hepatitis, etc.), recombinant DNA technology is increasingly used to produce rHSA in bacteria, yeast, and transgenic milk. 
It is the purpose of this report to outline a new, optimized downstream purification protocol for rHSA in the CCS of the highyielding, methylotrophic Pichia pastoris yeast grown in a fermentor. The main characteristics of the purified rHSA will also be presented.

\section{MATERIALS AND METHODS}

Sodium caprylate (octanoic acid, Na salt), and L-cysteine were bought from SIGMA chemical Co. Chromatographically purified HSA was kindly provided by I. Andersson at the plasma processing unit of GE Healthcare Bio-Sciences. The concentration of proteins in various samples was determined using a Bio-Rad Protein Assay kit (BCA, Bio-Rad Laboratories). Purified bovine serum albumin (BSA) was used to construct the standard curve. UV/Vis absorption measurements were made using a Shimadzu UV-160A recording spectrophotometer (Shimadzu Corporation, Japan). All other chemicals used were of analytical or reagent grade.

\section{Cell Culture Supernatant (CCS)}

The CCS was obtained from North China Pharmaceutical Group Corporation (NCPC). The genetically modified P. pastoris cells were fermented for 2 weeks or more, followed by separation of the cells by filtration. The CCS was stored in a frozen state $\left(-70^{\circ} \mathrm{C}\right)$ and sent to Uppsala, Sweden, for processing. The frozen sample was thawed, divided into $200 \mathrm{~mL}$ aliquots, and then stored at $-20^{\circ} \mathrm{C}$ for future use. The crude CCS was green to dark green in color.

The quality of the CCS was determined by gel filtration on an analytical column of Superdex ${ }^{\mathrm{TM}} 200 \mathrm{HR} 10 / 30\left(\mathrm{~V}_{\mathrm{t}}=23.6 \mathrm{~mL}\right)$ run on ÄKTAexplorer ${ }^{\mathrm{TM}} 100$ System. The column was equilibrated with $50 \mathrm{mM}$ sodium phosphate, $0.15 \mathrm{M} \mathrm{NaCl}, \mathrm{pH}$ 7.0. The crude CCS was found to contain $8-12 \mathrm{~g} / 1$ of HSA and albumin-derived products and was diluted $1+1$ with the equilibration buffer. An aliquot of $0.5 \mathrm{~mL}$ was applied to the column followed by elution with the equilibration buffer at a flow rate of $0.4 \mathrm{~mL} / \mathrm{min}(30 \mathrm{~cm} / \mathrm{h})$. The area under each of the eluted peaks (representing polymers, dimer, and monomer forms of rHSA as well as low molecular weight impurities) was calculated using the integration program of the UNICORN 3.2.1 software, from which the concentration of rHSA was determined using a standard curve. Such an analysis also gives a good estimate of the concentration of the LMW impurities in the product and thereby the quality of the CCS. 


\section{Analytical Gel Electrophoresis}

This was performed using a PhastGel ${ }^{\mathrm{TM}}$ electrophoresis system and appropriate media. The electrophoretic analyses were performed using native-PAGE $(8-25 \%)$ or SDS-PAGE (non-reduced, 10-15\%) gels according to the manufacturer's recommendations. The amount of sample applied per spot was approx. $3.3 \mu \mathrm{g}$ for the native samples and $2 \mu \mathrm{g}$ for the SDS-treated samples. Both types of gels were stained with the Silver Staining Kit (GE Healthcare Bio-Sciences). For the SDS-treated samples that were stained with Coomassie Brilliant Blue (CBB), the amount of sample applied was $10 \mu \mathrm{g}$.

\section{Iso-Electric Focusing}

This analysis was performed on Immobiline ${ }^{\mathrm{TM}}$ Dry Strips 4-7 and 3-10 isoelectric focusing gel using an IPGphor ${ }^{\mathrm{TM}}$ apparatus (GE Healthcare BioSciences). Each sample was treated with $8 \mathrm{M}$ urea and suitable aliquots were applied to the gel. The focusing of the gel and subsequent staining were performed according to procedures recommended by the manufacturer.

\section{Mass Spectrometry}

Mass spectrometric analyses (aimed at determining the mass of purified rHSA and plasma-derived HSA) were performed by Dr. J. Flensburg at GE Healthcare Bio-Sciences using the MALDI-ToF technique. Peptide mapping of the tryptic digests of native and recombinant HSA was also performed using this technique. The results obtained served as the basis for establishing the most probable primary sequence of the rHSA with reference to the known sequences of tryptic peptides generated from native HSA.

\section{High Performance Reversed Phase Chromatography (HP-RPC)}

HP-RPC of purified rHSA and HSA was performed on an analytical column (4.6 i.d. $\times 150 \mathrm{~mm}, \mathrm{Vt}=2.49 \mathrm{~mL})$ of SOURCE ${ }^{\mathrm{TM}} 5 \mathrm{RPC}(\mathrm{GE}$ Healthcare Bio-Sciences) using elution conditions that were specifically optimized for this analysis.

\section{EXPERIMENTAL}

\section{Media and Chromatography System}

All chromatographic experiments were performed at room temperature (approximately $22^{\circ} \mathrm{C}$ ) using an ÄKTAexplorer 100 system. The following 
chromatographic media were used in this investigation: Capto $^{\mathrm{TM}} \mathrm{MMC}$ (a newly introduced multi-modal, high salt tolerant cation-exchanger based on Sepharose ${ }^{\mathrm{TM}} 6$ Fast Flow base matrix), lot 297815; Phenyl Sepharose ${ }^{\mathrm{TM}}$ 6 Fast Flow (high sub), lot 297109 and Aminobutyl Sepharose ${ }^{\mathrm{TM}} 6$ Fast Flow, lot 297868. Its adsorption characteristics are similar to DEAE Sepharose ${ }^{\mathrm{TM}}$ Fast Flow but it is much more effective in removing the LMW impurities.

The media were packed in glass columns according to standardized procedures. A linear flow rate of $300 \mathrm{~cm} / \mathrm{h}$ was used throughout. Each packed column was washed with 2 bed volumes of de-ionized water to elute most of the ethanol used as a preservative and then equilibrated with the appropriate buffer solution prior to sample application. The amount of buffer required for each of the chromatographic steps is described under the appropriate sections.

\section{Buffer Solutions}

Buffer A

$25 \mathrm{mM}$ sodium acetate, $\mathrm{pH} 4.5$ (Conductivity $=2 \mathrm{mS} / \mathrm{cm}$ at $22^{\circ} \mathrm{C}$ ).

Buffer B

$50 \mathrm{mM}$ sodium phosphate, $0.1 \mathrm{M} \mathrm{NaCl}, 10 \mathrm{mM}$ sodium caprylate, $\mathrm{pH}$ 7.0. $\left(\right.$ Conductivity $=16 \mathrm{mS} / \mathrm{cm}$ at $\left.22^{\circ} \mathrm{C}\right)$.

Buffer C

$50 \mathrm{mM}$ sodium phosphate, $0.1 \mathrm{M} \mathrm{NaCl}$, pH 6.0. (Conductivity = $14 \mathrm{mS} / \mathrm{cm}$ at $22^{\circ} \mathrm{C}$ ).

Buffer D

$50 \mathrm{mM}$ sodium phosphate, $0.2 \mathrm{M} \mathrm{NaCl}$, pH 6.0. (Conductivity $=$ $22 \mathrm{mS} / \mathrm{cm}$ at $22^{\circ} \mathrm{C}$ ).

Buffer E

$30 \%$ iso-propanol dissolved in $1 \mathrm{M} \mathrm{NaOH}$ solution (for cleaning in place).

\section{Heat Treatment of the CCS}

This operation is performed mainly to inactivate proteolytic enzymes produced by the $P$. pastoris cells during fermentation. The frozen CCS 
was thawed and $10 \mathrm{mM}$ Na-caprylate was dissolved in it. Its $\mathrm{pH}$ was adjusted to 6.0 and the flask container was immersed in a thermostated water bath (maintained at $68^{\circ} \mathrm{C}$ ) for $30 \mathrm{~min}$. The sample was then cooled to room temperature and its $\mathrm{pH}$ adjusted to 4.5. In most instances, the CCS was clear after the heat treatment and a further centrifugation step was not necessary. The conductivity of this solution was approximately $16 \mathrm{mS} / \mathrm{cm}$ at $22^{\circ} \mathrm{C}$, and further dilution of the sample was not necessary for the initial capture step as long as the conductivity of the sample was less than approximately $30 \mathrm{mS} / \mathrm{cm}$.

\section{Chromatography}

The Capture Step

The Capto MMC medium was packed in an XK16/20 column (bed volu$\mathrm{me}=20 \mathrm{~mL}$ ) and washed with 4 column volumes $(\mathrm{CV})$ of Buffer A to equilibrate the column. Approximately $150 \mathrm{~mL}$ of the heat-treated CCS (total protein content $=1 \mathrm{~g}$ ) was applied to the column at a flow rate of $300 \mathrm{~mL} / \mathrm{h}(150 \mathrm{~cm} / \mathrm{h})$. The amount of $\mathrm{rHSA}$ applied corresponds to $50 \mathrm{mg} \mathrm{rHSA} / \mathrm{mL}$ of packed medium. After sample application, the unbound material was eluted with $3 \mathrm{CV}$ of Buffer A followed by elution of the bound rHSA with $5 \mathrm{CV}$ of Buffer $\mathrm{B}$. The two fractions were pooled separately and the $\mathrm{pH}$ of the bound fraction was adjusted to 6.0 with $1 \mathrm{M}$ $\mathrm{NaOH}$. It was then heated for $60 \mathrm{~min}$ at $60^{\circ} \mathrm{C}$ in the presence of $10 \mathrm{mM}$ each of cysteine and $\mathrm{Na}$-caprylate and cooled to room temperature prior to further purification on a HIC column as described in section 3.4.2. The main purpose of this operation was to facilitate the removal of colored substances by the HIC adsorbent.

The Capto MMC medium was regenerated by a wash with $2 \mathrm{CV}$ of Buffer E and storing the column overnight in this solution. It was then washed with $4 \mathrm{CV}$ of de-ionised water to elute most of the $\mathrm{NaOH} /$ iso-propanol solution followed by equilibration with Buffer A (4 CV) for the next cycle of operation.

\section{The Intermediate Purification Step}

The heat-treated fraction was applied to an XK26/20 column packed with Phenyl Sepharose 6 Fast Flow (high sub) to a bed volume of $40 \mathrm{~mL}$. The column was equilibrated with $3 \mathrm{CV}$ of Buffer C. After sample application, the column was washed with $2 \mathrm{CV}$ of Buffer $\mathrm{C}$ to elute the unbound fraction which contained the rHSA. The bound fraction which contained mainly the $45 \mathrm{kDa}$ degraded form of rHSA, was eluted with $2 \mathrm{CV}$ of de-ionised water. The flow rate was maintained at $150 \mathrm{~cm} / \mathrm{h}$ 
Table 1. The number of CV of equilibration, elution and re-generation solutions required for each of the three chromatographic steps outlined above

\begin{tabular}{lccccc}
\hline Medium & Equilibrate & Wash & Elute & CIP & Wash with* \\
\hline Capto MMC* & $4[\mathrm{~A}]$ & $3[\mathrm{~A}]$ & $5[\mathrm{~B}]$ & $2[\mathrm{E}]$ & 4 \\
Phenyl Sepharose (hs) & $3[\mathrm{C}]$ & $2[\mathrm{C}]$ & $2\left[{ }^{*}\right]$ & $2[\mathrm{E}]$ & 4 \\
Aminobutyl Sepharose & $6[\mathrm{C}]$ & $2[\mathrm{C}]$ & $5[\mathrm{D}]$ & $2[\mathrm{E}]$ & 4 \\
\hline
\end{tabular}

Letters in brackets refer to the buffer list presented above.

$*=$ de-ionized water.

throughout. After this operation, the column was regenerated by a wash with $2 \mathrm{CV}$ of Buffer $\mathrm{E}$ followed by $4 \mathrm{CV}$ of de-ionized water.

\section{The Polishing Step}

A column (XK26/20) was packed with Aminobutyl Sepharose 6 Fast Flow to yield a bed volume of $40 \mathrm{~mL}$. The column was then washed with $2 \mathrm{CV}$ of de-ionized water followed by equilibration with $6 \mathrm{CV}$ of Buffer $\mathrm{C}$. To this column was applied $60 \mathrm{~mL}$ of pooled fraction $2 \mathrm{~A}$ (defined in Fig. 2) followed by a wash with $2 \mathrm{CV}$ of Buffer $\mathrm{C}$ to elute the unbound fraction $3 \mathrm{~A}$ (defined in Fig. 3). The bound fraction was then eluted with $5 \mathrm{CV}$ of Buffer D. The medium was regenerated by washing with $2 \mathrm{CV}$ of Buffer $\mathrm{E}$ followed by $4 \mathrm{CV}$ of de-ionized water. It was then equilibrated by passing $6 \mathrm{CV}$ of Buffer $\mathrm{C}$ in preparation for the next cycle of operation. The flow rate was maintained at $150 \mathrm{~cm} / \mathrm{h}$ throughout.

The elution protocols were optimized for each of the media used above and are summarised in Table 1. This table is useful when scaling up the process to pilot- or production-scale operations (to be discussed elsewhere).

\section{CRITERIA FOR ACCEPTANCE}

A general requirement for proteins produced by recombinant DNA technology is their identity with their natural counterparts. Other minimum requirements include tests for purity, potency, toxicity, pyrogenicity etc. (12), which are necessary to assure the safety of the product as a biopharmaceutical. Further considerations such as stability (13) and binding characteristics $(14,15)$ might be added to the list. Here follows a tentative list of criteria for acceptance of a purified rHSA.

1. The level of pigments in a $25 \%$ solution of purified rHSA may be in the range of $0.01-0.05$ in terms of an $\mathrm{A}_{350} / \mathrm{A}_{280}$ ratio (2). 
2. The electrophoretic homogeneity should be greater than $99.99 \%$ as determined by gradient SDS-PAGE performed under reducing and non-reducing conditions. In those instances where bands other than the monomer and dimer forms of rHSA are observed on the gel, Western blot analysis should be performed using appropriate antibodies to identify which band(s) are extraneous protein impurities.

3. The content of dimer and polymers of rHSA should be significantly less than $2 \%$ as determined by non-reducing, gradient SDS-PAGE analysis or by gel filtration.

4. The content of yeast-derived proteins and polysaccharides (as determined by total ELISA) at a sample concentration of $25 \%$ should both be less than $0.1 \mathrm{ng} / \mathrm{mL}$ (3).

5. The amount of contaminating DNA, as determined by the total threshold method, should be less than $1 \mathrm{pg} / \mathrm{mL}$ in a $25 \%$ solution of purified rHSA.

6. The purified rHSA should be free from degradation products of rHSA.

7. Test for pyrogen content should be negative at a dose of $0.75 \mathrm{~g}$ of purified rHSA per $\mathrm{kg}$ of rabbit.

8. Test for sterility should satisfy the requirements of the European Pharmacoepia (1997) and its 1998 Supplement.

9. Test for stability: The sample of purified rHSA, appropriately formulated by including stabilisers (e.g. sodium caprylate), is heated in a water bath for $50 \mathrm{~h}$ at $57^{\circ} \mathrm{C}$. No visible change should be observed relative to a control sample.

10. Free fatty acid content should correspond to that in plasma-derived HSA.

\section{RESULTS AND DISCUSSION}

As a consequence of this investigation, two new chromatographic media (i.e. Capto MMC and Aminobutyl Sepharose ) have been introduced. Their use has resulted in improved recovery, purity, and homogeneity of the rHSA and has simplified the downstream purification process, as detailed in Table 2. Each chromatographic step has also been optimized in detail with respect to recovery, electrophoretic homogeneity, level of rHSA dimer, and reduction in the level of pigments (expressed as the $A_{350} / A_{280}$ ratio).

The batch to batch variation of the CCS with respect to pigments, protein content, and LMW degradation products was found to be significant. Consequently, the quality of the CCS was checked by gel filtration on a column of Superdex HR 10/30 as outlined above. Only those 
Table 2. Summary of the analyses performed on the main fractions obtained in Figs. 1-3

\begin{tabular}{|c|c|c|c|c|c|c|c|c|c|}
\hline Pool & $\begin{array}{l}\text { Volume } \\
\text { (mL) }\end{array}$ & $\mathrm{A}_{280}$ & $\begin{array}{l}\text { Total } \\
\mathrm{A}_{280}\end{array}$ & $\begin{array}{c}\% \text { of } \\
\text { applied }\end{array}$ & $\mathrm{A}_{350}$ & $\begin{array}{l}\mathrm{A}_{350} / \\
\mathrm{A}_{280}\end{array}$ & $\begin{array}{l}\text { protein conc. } \\
(\mathrm{mg} / \mathrm{mL})\end{array}$ & $\begin{array}{l}\text { Total } \\
\text { Protein } \\
(\mathrm{mg})\end{array}$ & $\begin{array}{c}\text { Recovery } \\
(\%)\end{array}$ \\
\hline CCS & 147 & 16.94 & 2490 & 100.0 & 2.645 & 0.156 & 6.45 & 948 & 100 \\
\hline $1 \mathrm{~A}$ & 188 & 12.18 & 2289 & 92 & 2.265 & 0.186 & 0.81 & 152 & 16 \\
\hline 1B & 43 & 11.07 & 476 & 19 & 1.833 & 0.166 & 15.22 & 654 & 69 \\
\hline $2 \mathrm{~A}$ & 61 & 4.84 & 297 & 69 & 0.418 & 0.086 & 7.58 & 466 & 80 \\
\hline $2 B$ & 27 & 2.12 & 57 & 13 & 0.599 & 0.283 & 0.54 & 14 & 3 \\
\hline $3 \mathrm{~A}$ & 76 & 0.16 & 12 & 4 & 0.019 & 0.118 & 0.00 & 0.0 & 0 \\
\hline $3 B$ & 83 & 1.88 & 155 & 54 & 0.060 & 0.032 & 3.55 & 295 & 65 \\
\hline
\end{tabular}

batches of CCS that had relatively low levels of LMW degradation products and pigments were chosen for this investigation.

\section{The Cell Culture Supernatant (CCS)}

The major impurities in the CCS are LMW substances which are negatively charged over a wide range of $\mathrm{pH}$ values. On the other hand, rHSA is positively charged at $\mathrm{pH}$ values lower than its $\mathrm{pI}$ (approximately $\mathrm{pH}$ 5). This difference in surface charge of the major components of the CCS has been exploited when devising the initial purification step for rHSA. At the capture step, the rHSA is bound to the Capto MMC cation exchanger at $\mathrm{pH} 4.5$ while most of the LMW impurities are eluted without retardation. This approach has the added advantage that the Capto MMC medium can easily be regenerated. It is also conceivable that one can use an anion-exchanger instead of the Capto MMC at this capture step. In such a case, the LMW impurities would be bound while the rHSA would be eluted in the unbound fraction. However, when tested, this approach proved to be unsuccessful since the LMW pigments were bound to the anion exchanger so strongly that regeneration of the medium was rendered very difficult. On the basis of these findings, Capto MMC was used as the chromatographic medium of choice at the capture step. In the following paragraphs, the salient features of the three downstream purification steps for rHSA are summarised.

\section{The Capture Step}

The elution pattern obtained after chromatography of $147 \mathrm{~mL}$ of the heat-treated CCS (containing approximately $1 \mathrm{~g}$ of rHSA) on a $20 \mathrm{~mL}$ 
packed column of Capto MMC is shown in Fig. 1. Details of the experimental set up are described in section 3.4.1. The two pooled fractions (1A and $1 B$ ) were analysed with respect to $A_{280}$, protein content, $A_{350} / A_{280}$ ratio (which is a rough estimate of the level of pigments) and the recovery of applied material in terms of protein content (total $\mathrm{A}_{280}$ ) of each pooled fraction relative to the material applied on the column. The results obtained are compiled in Table 2. The electrophoresis patterns of the CCS and pooled fractions $1 \mathrm{~A}$ and $1 \mathrm{~B}$ (under reduced and non-reduced conditions) are shown in Fig. 4. The results obtained show that Fraction $1 \mathrm{~A}$ accounts for $92 \%$ of the $A_{280}$ and only $16 \%$ of the protein applied to the column. This discrepancy is most likely due to the high $\mathrm{A}_{280}$ absorbance of the impurities which, to a large extent, are not proteins. This is clearly seen on the SDS-PAGE patterns of fractions $1 \mathrm{~A}$ and $\mathrm{BB}$ after staining with Coomassie Brilliant Blue (see Lane 2 in Fig. 4) where the protein bands are barely visible. However, due to the high sensitivity of the silver staining method, several bands are seen in Lane 2.

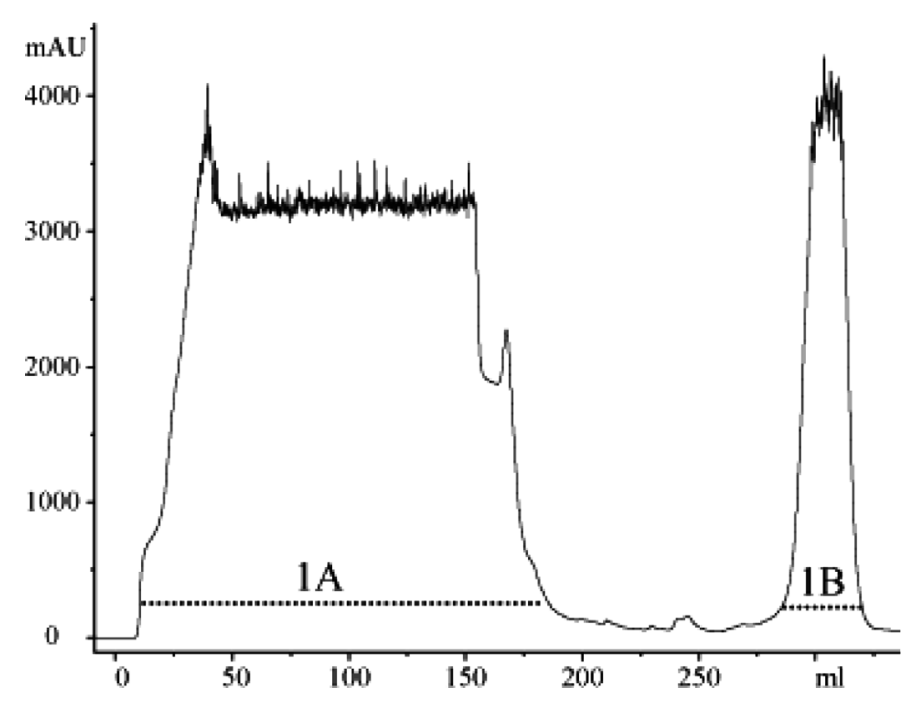

Figure 1. Chromatography of $147 \mathrm{~mL}$ of heat-treated CCS (containing $1 \mathrm{~g}$ of total protein) on a $20 \mathrm{ml}$ column of Capto ${ }^{\mathrm{TM}} \mathrm{MMC}$ equilibrated with Buffer A. After sample application, the unbound fraction (1A) was eluted with $3 \mathrm{CV}$ of Buffer A followed by elution of the bound fraction (1B) with $5 \mathrm{CV}$ of Buffer B. This latter fraction contains the partially purified rHSA. The linear flow rate was maintained at $150 \mathrm{~cm} / \mathrm{h}$ throughout. For more experimental details, see text. The content of proteins, pigments $\left(\mathrm{A}_{350} / \mathrm{A}_{280}\right)$, and recovery of applied material are summarized in Table 2. Results of the electrophoretic analyses of the 2 fractions obtained here are shown in Fig. 4. 
As will be shown further on, these bands are effectively removed after the ensuing two chromatographic steps.

Capto MMC is a new cation-exchanger designed for binding proteins at relatively high concentrations of salts (up-to $30 \mathrm{mS} / \mathrm{cm}$ ) without significantly affecting its adsorption characteristics. This obviates the need for dilution of the CCS prior to application to the packed medium. In the present case, the adsorption capacity of the Capto MMC medium was in the range of $50 \mathrm{mg}$ of $\mathrm{rHSA} / \mathrm{mL}$ of packed medium. Under the same experimental conditions, SP Sepharose Big Beads bind a mere $2-4 \mathrm{mg} / \mathrm{mL}$ of rHSA. However, these two media have almost the same adsorption capacities for rHSA of approximately $50 \mathrm{mg} / \mathrm{mL}$ when the conductivity of the CCS is approximately $10 \mathrm{mS} / \mathrm{cm}$ or less. It is thus apparent that the salttolerant Capto MMC medium can simplify and improve the initial capture step for purifying rHSA and thereby significantly reduce the cost for operating the entire purification process on a large-scale.

\section{The Intermediate Purification Step}

A further purification of the rHSA in pooled fraction 1B was achieved by HIC on a $40 \mathrm{~mL}$ column of Phenyl Sepharose 6 Fast Flow (high sub). The column was equilibrated with Buffer $\mathrm{C}$ and $40 \mathrm{~mL}$ of fraction 1B (containing approx. $580 \mathrm{mg}$ of protein) was applied to it followed by elution with Buffer $\mathrm{C}$ to wash out the unbound fraction $2 \mathrm{~A}$. The bound fraction $2 \mathrm{~B}$ was eluted with de-ionised water. For further experimental details, see section 3.4.2.

The elution profile obtained after this chromatographic step is shown in Fig. 2. The results of the analyses performed on each of the fractions $2 \mathrm{~A}$ and $2 \mathrm{~B}$ with respect to $\mathrm{A}_{350} / \mathrm{A}_{280}$ ratio, total protein content, recovery, etc. are summarized in Table 2. The native/SDS PAGE analyses of fractions 2A and 2B are shown in Fig. 4 (Lanes 4 and 5). These results indicate that the rHSA is not bound to the HIC column while the impurities are bound. This result is interesting by itself and is a rare finding in HIC of macromolecules since the adsorption occurs in very low salt concentration (in this case $0.1 \mathrm{M} \mathrm{NaCl}$ ). Normally, significantly higher salt concentrations $(0.5 \mathrm{M}$ and more) are required for the adsorption step in HIC. The successful outcome obtained here is due to a combination of high ligand concentration of the HIC medium, low concentration of salt in the mobile phase, and high hydrophobiciy of the solute in the bound fraction 2B. According to the electrophoretic patterns shown in Fig. 4 (lane 5), the main band is the $45 \mathrm{kDa}$ proteolytic degradation product of rHSA).

The volume of the HIC medium used in this step $(40 \mathrm{~mL})$ is twice that used at the capture step $(20 \mathrm{~mL})$ which reflects the relatively low 


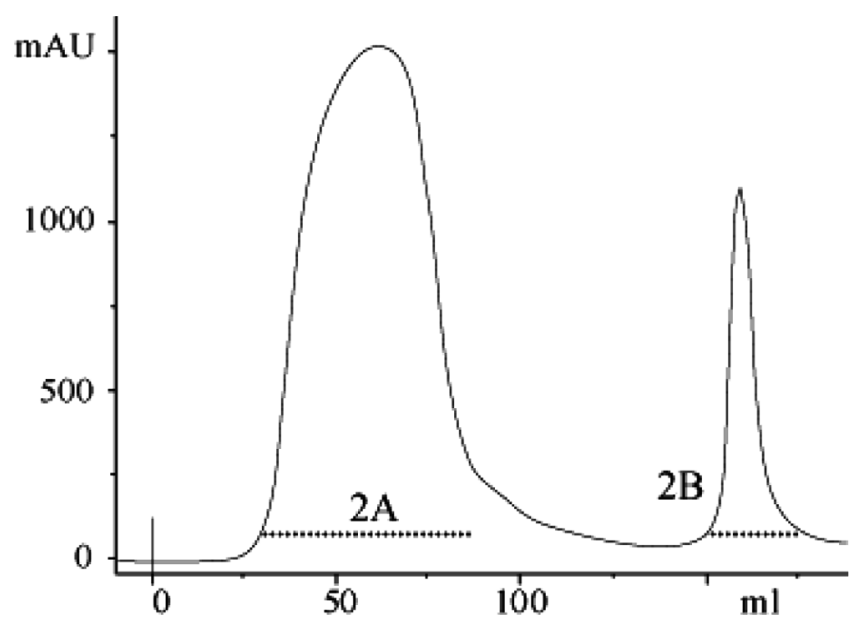

Figure 2. Chromatography of $40 \mathrm{~mL}$ of heat-treated fraction $1 \mathrm{~B}$ on a $40 \mathrm{ml}$ column of Phenyl Sepharose ${ }^{\mathrm{TM}} 6$ Fast Flow (high sub) equilibrated with Buffer C. The unbound fraction (2A), which contains the partially purified rHSA, was eluted with $2 \mathrm{CV}$ of Buffer C. The bound fraction (2B) was eluted with de-ionized water. For more experimental detail, see text.

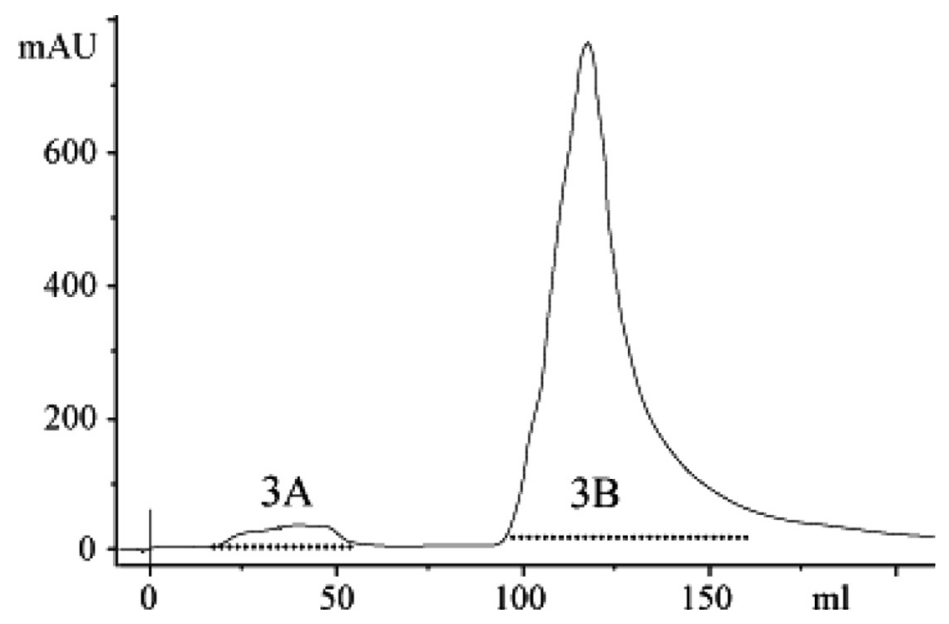

Figure 3. Elution profile obtained after chromatography of $60 \mathrm{~mL}$ of pooled fraction $2 \mathrm{~A}$ on a $40 \mathrm{~mL}$ column of Aminobutyl Sepharose ${ }^{\mathrm{TM}} 6 \mathrm{FF}$ equilibrated with Buffer C. For experimental details, see text. 
adsorption capacity of HIC media relative to IEC media. To compensate for this, one can conceivably increase the salt concentration used in the equilibration buffer C. However, this approach leads to a gradual increase in the amount of rHSA bound to the column, in turn resulting in a loss of the target product. It is also worth noting that this step leads to a significant decrease in the content of coloured pigments in the partially purified rHSA (down from 0.142 to 0.086 ). The recovery of the target protein (almost exclusively rHSA in fraction $3 \mathrm{~A}$ ) was $80 \%$ (see Table 2). The impurities in fraction $3 \mathrm{~B}$ accounted for a mere $2.5 \%$ of the total protein applied to the column. The total recovery in this step is thus approx. $83 \%$ and the loss of material $(10-15 \%)$ is most likely due to a very strong binding of the impurities to the HIC medium to the extent that they could not be eluted by de-ionised water.

\section{The Polishing Step}

This is the last step in the chromatographic purification of rHSA and involves the removal of traces of the LMW impurities in pooled fraction

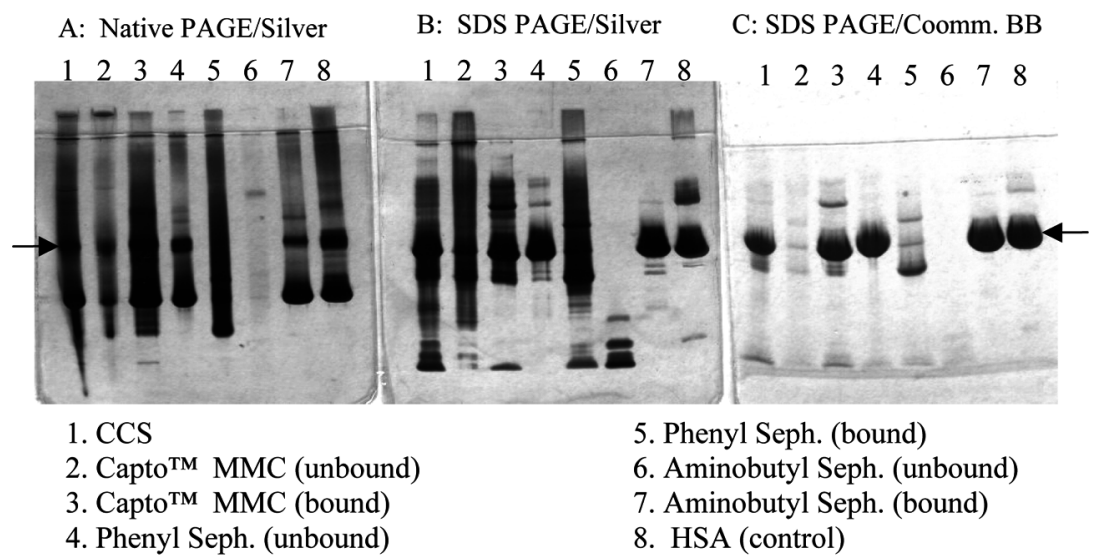

The arrows show the positions of rHSA

Seph. $=$ Sepharose ${ }^{\mathrm{TM}} 6$ Fast Flow

Figure 4. Native PAGE (8-25\%) and SDS-PAGE (10-15\%) analyses of the main fractions obtained after each of the three purification steps for rHSA. For the native-PAGE gel visualized by silver staining (Plate A), ca. $3.3 \mu \mathrm{g}$ of protein per spot was applied. For the SDS-PAGE gels visualized by silver staining (Plate B), ca. $2 \mu \mathrm{g}$ of protein per spot was applied. For the SDS-PAGE gel visualized by Coomassie staining (Plate $\mathrm{C}$ ), ca. $10 \mu \mathrm{g}$ of protein per spot was applied. 
2A. The elution profile obtained after chromatography of $60 \mathrm{~mL}$ of fraction $2 \mathrm{~A}$ on a $40 \mathrm{~mL}$ column of Aminobutyl Sepharose is shown in Fig. 3. The results of the analyses performed on pooled fractions $3 \mathrm{~A}$ and $3 \mathrm{~B}$ with respect to several parameters are presented in Table 2. The native/SDS PAGE analyses of fractions $3 \mathrm{~A}$ and $3 \mathrm{~B}$ after silver/ Coomassie staining are shown in fig. 4. On the basis of these results, the following general conclusions are made.

The small amount of remaining LMW impurities in the applied sample (2A) is effectively removed after this step as shown by SDS-PAGE analysis (see Lane 6 in Fig. 4). The level of protein in this fraction is also very low, or virtually zero, as shown in Table 2 . On the other hand, the $\mathrm{A}_{350} / \mathrm{A}_{280}$ of this fraction is very high (0.118) indicating that the Aminobutyl Sepharose medium is very effective in removing pigments as well. The level of pigments in the bound fraction (3B) is quite low (0.032) and is close to the level that is acceptable for purified HSA. The native/SDS PAGE patterns of the purified rHSA indicate the presence of a single, major band (Fig. 4, Lane 7) that migrates to the same position as a highly purified, plasma-derived HSA. As a matter of fact, the rHSA purified by the process outlined here is more homogeneous than its natural counterpart, as judged by the absence of the dimer form of rHSA in Fig. 4.

\section{SOME CHARACTERISTICS OF THE PURIFIED rHSA}

In the following sections, the main molecular and physical characteristics of purified rHSA will be outlined. The list is by no means exhaustive and is intended mainly to provide further evidence as to the identity of the purified rHSA vis á vis its natural counterpart, i.e. plasmaderived HSA.

\section{Purity and Identity}

The gel filtration patterns of purified rHSA and of three highly purified commercial preparations of plasma-derived HSA were analyzed on a column of Superdex $200 \mathrm{HR}$ 10/30. (For experimental details, see section 2.1.) The results obtained indicated that all 4 preparations of HSA eluted at the same position as single, symmetrical peaks. Furthermore, the content of the dimer form of the rHSA, if any, is significantly lower than that of the other 3 preparations. The results obtained here are in agreement with those obtained from SDS-PAGE on 10-15\% gradient gels, thereby confirming the conclusions reached earlier that the rHSA purified from the CCS of $P$. pastoris is of the highest purity. 
The iso-electric points of purified rHSA and a commercially purified HSA were determined as described in section 2.3. The results obtained indicate that both proteins are focused into 5 main bands to the same positions in the $\mathrm{pH}$ range of 5.42-5.55. This small difference in the focusing range $(0.13 \mathrm{pH}$ units) of both proteins suggests that the various bands arise from micro-heterogeneities in the surface charges of both albumin species. Iso-electric focusing in the $\mathrm{pH}$ range of 3-10 was also performed mainly to check the presence of any protein impurity that has a $\mathrm{pI}$ outside the range of the $\mathrm{pH} 4.0-7.0$ focusing gel. The results obtained clearly show the absence of any protein impurity in the purified rHSA sample. They also indicate that purified HSA and rHSA are, for all practical purposes, identical proteins.

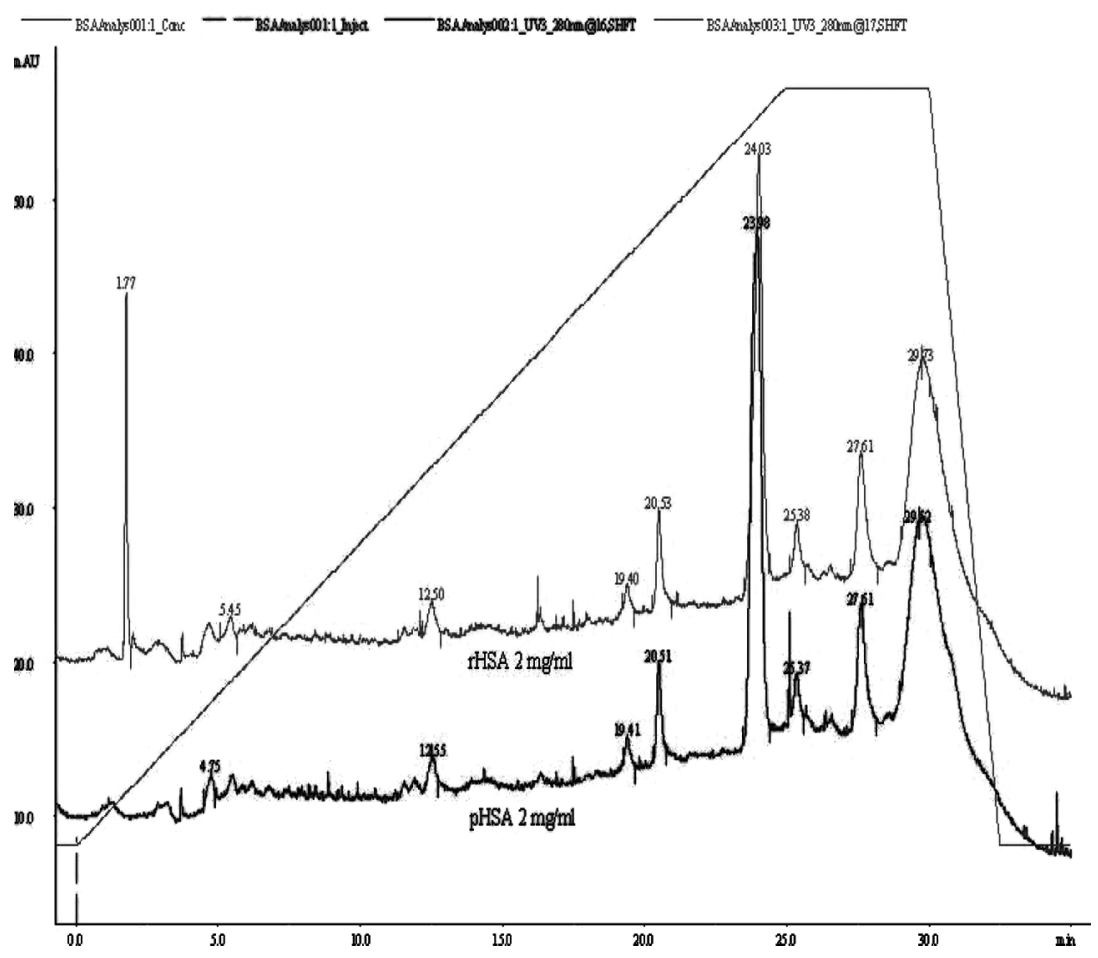

Figure 5. HP-RPC analysis of purified rHSA \& plasma-derived HSA on a column $(4.6 \times 150 \mathrm{~mm}, \mathrm{Vt}=2.49 \mathrm{~mL})$ packed with SOURCE ${ }^{\mathrm{TM}} 5 \mathrm{RPC}$. The following buffers were used: [A]: 0.065 TFA in water and, [B]: $0.05 \%$ TFA in 100\% acetonitrile. The column was equilibrated with a mixture of $96.5 \%$ Buffer A $+3.5 \%$ Buffer B. After application of $10 \mu \mathrm{L}$ of a $2 \mathrm{mg} / \mathrm{mL}$ solution of each sample $(20 \mu \mathrm{g}$ each), the column was eluted with a linear gradient from $3.5 \%$ to $49 \%$ Buffer B in $5 \mathrm{CV}$. The flow rate was $360 \mathrm{~cm} / \mathrm{h}$ throughout the experiment. 
The elution patterns obtained after chromatography of purified rHSA and plasma-derived HSA on an analytical column of SOURCE 5 RPC were identical in the smallest of details (data not shown) (Fig. 5). The results obtained thus provide convincing evidence that these two proteins are identical, at least with respect to their surface hydrophobicities and possibly also their structures.

\section{Structural and Molecular Characteristics}

The molecular masses of purified HSA, and 2 batches of purified rHSA, were determined by mass spectrometry using a $M A L D I-T o F$ instrument operating in a linear mode. The intensities and $\mathrm{m} / \mathrm{z}$ (mass vs. charge) profiles for both proteins were identical indicating a close relationship in the mass of HSA and rHSA (Fig. 6). Purified HSA and rHSA were also subjected to digestion with trypsin and the peptides so generated were analysed directly by a MALDI-ToF instrument operating in a reflection mode. The $\mathrm{m} / \mathrm{z}$ (mass/charge) values obtained for each digest were transferred to a search engine (ProFound) which resulted in $40 \%$ coverage of the proteins and which assigned HSA as the highest rated candidate. Taken together, the results from determinations of full length proteins and peptide mass finger printing by MALDI-ToF clearly demonstrated that the natural and recombinant forms of HSA have identical amino acid compositions (a total of 585 residues for each protein).

The amino acid sequences of 2 of the peptide fragments generated from rHSA were also determined by MALDI-ToF and post source dissociation (PSD) after chemical derivatization. One such peptide was situated at position 403-410 and had the sequence: Phe-Gln-Asn-AlaLeu-Leu-Val-Arg. A second fragment was situated at position 42-47 and had the sequence: Leu-Ile-Val-Asn-Glu-Val. The sequences and positions of these 2 peptide fragments were identical to those of their natural counterparts offering further evidence that the natural and recombinant forms of HSA are identical proteins.

\section{Stability}

The CCS of $P$. pastoris contains proteolytic enzymes that digest rHSA to LMW degradation products. In order to limit the extent of proteolysis of rHSA during the downstream purification process, it is a routine procedure to adjust the $\mathrm{pH}$ of the CCS to 6.0 , followed by a heat treatment for $30 \mathrm{~min}$ at $68^{\circ} \mathrm{C}$ in the presence of $10 \mathrm{mM}$ sodium caprylate as a stabiliser. In order to appreciate the extent of protection such a treatment affords to purified HSA, as well as to investigate the effects of exposing 


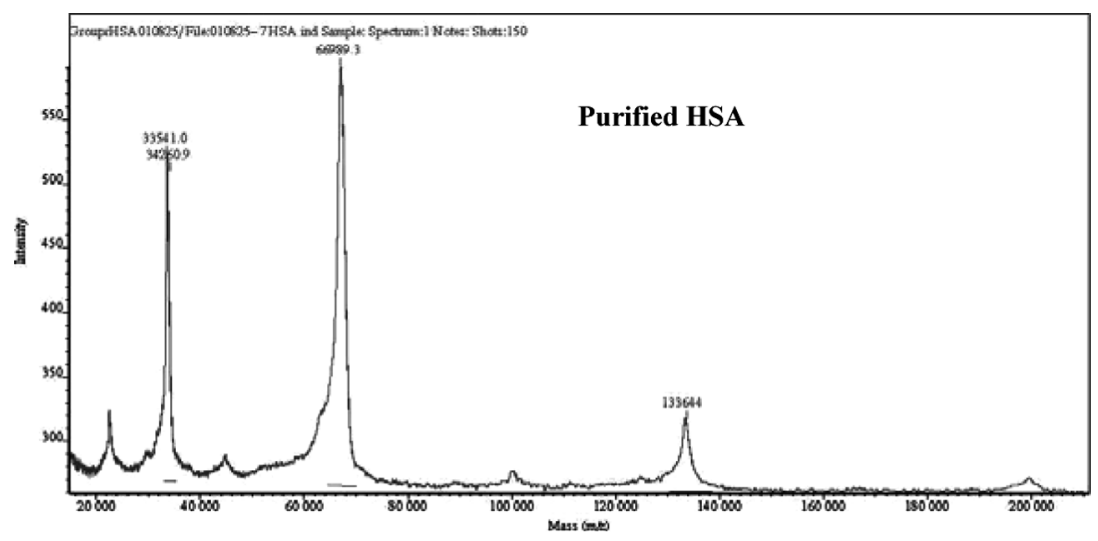

(a)

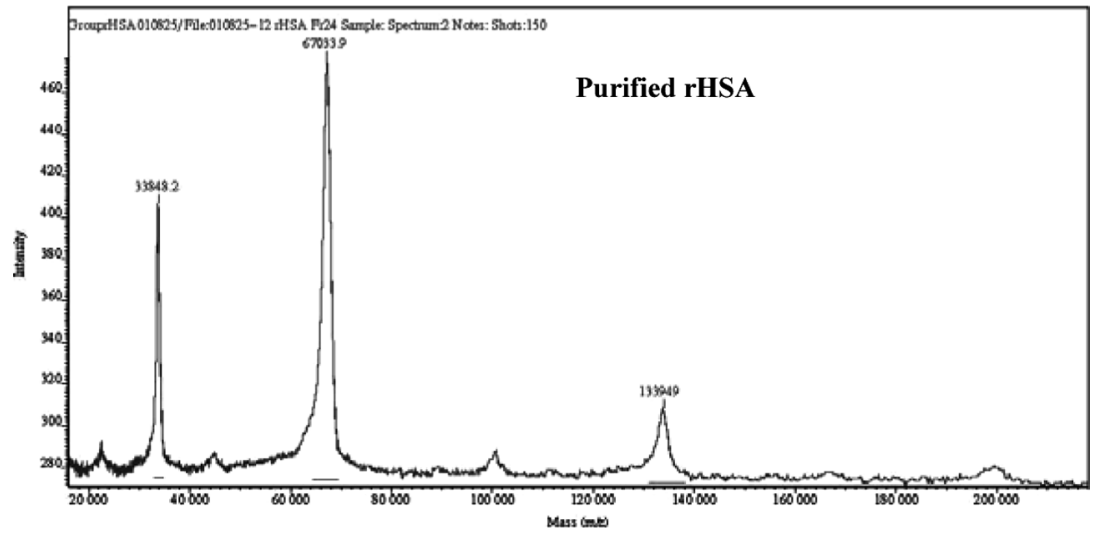

(b)

Figure 6. Intensity vs. $m / z$ spectra of purified HSA and rHSA obtained after running each full-length protein on an Ettan MALDI-ToF mass spectrometer. The numbers on top of each peak represent the molecular mass of: peak I (double-charged monomeric HSA); peak II (monomeric HSA) and peak III (dimeric HSA). For purified HSA, the molecular mass of peak $\mathrm{I}=33541$; that of peak II $=66989$ and that of peak III = 133 644. The corresponding masses obtained for rHSA are: peak I = 33 848; peak II = 67033 and peak III = 133949 .

HSA to other types of treatments, a series of experiments were performed. The results obtained indicate that:

1. Na-caprylate protects purified HSA from aggregation during a $30 \mathrm{~min}$ heat treatment at $68^{\circ} \mathrm{C}$.

2. Purified HSA forms aggregate when heated for $30 \mathrm{~min}$ at $68^{\circ} \mathrm{C}$ in the presence of $10 \mathrm{mMCys}$, probably as a result of the reduction of 
disulphide bonds followed by disulphide exchange reactions. Heating purified HSA for $30 \mathrm{~min}$ at $68^{\circ} \mathrm{C}$ in the presence of $10 \mathrm{mM}$ each of $C y s$ and Na-caprylate stabilises its structure and markedly reduces the level of dimer. At the same time, some LMW material is also formed.

3. Purified rHSA heated for $5 \mathrm{~min}$ at $100^{\circ} \mathrm{C}$ in the presence of $1 \% \mathrm{SDS}$ forms detectable amounts of LMW bands. This finding has direct relevance when establishing the electrophoretic homogeneity of purified rHSA preparations.

The stability of purified rHSA towards high temperatures has also been established using differential scanning calorimetric (DSC) analysis. The thermal stability of a protein is readily determined by this method which records the excess heat capacity of a protein solution as a function of temperature. This record, or "thermogram," is linear for temperatures where no unfolding takes place but departs from linearity when the protein undergoes unfolding, aggregation, or any other chemical or physical process. The melting point $\left(\mathrm{T}_{\mathrm{m}}\right)$ is defined as that temperature for which the excess heat capacity is at its maximum.

Melting points were recorded for purified rHSA and for six commercial HSA products. All were dissolved in a phosphate buffer $(10 \mathrm{mM})$ containing $10 \mathrm{mM}$ sodium caprylate. A comparison between these samples showed identical stability for the control HSA and the rHSA purified in this work. The remaining five HSA samples were similar to one another, but showed a somewhat lower melting temperature than the rHSA. Removal of caprylate (by gel filtration on a PD10 column) resulted in a significant destabilization of the plasma-derived, commercial HSA. The purified rHSA appeared to be somewhat less affected by this operation.

\section{CONCLUSIONS}

A three step chromatographic procedure has been devised for purifying rHSA from the CCS of genetically transformed $P$. pastoris cells grown in a fermentor. The downstream purification process is reproducible, robust and well suited for scaling-up to a large scale operation. The characteristics of the three chromatographic media are easily restored by a standard CIP procedure making it possible to use these media for several cycles of adsorption and de-sorption processes, thereby reducing significantly the material and operational costs for the entire downstream purification process. The structural and molecular characteristics of the purified rHSA, as well as its stability, are indistinguishable from its natural counterpart, i.e. human plasma-derived HSA by the criteria used here. 


\section{ACKNOWLEDGEMENTS}

This investigation was carried out at the Centre for Surface Biotechnology (CSB), University of Uppsala, Biomedical Centre, Uppsala, Sweden with funds in part provided by GE Healthcare Bio-sciences. The Project was carried out according to a mutual agreement between the CSB and GE Healthcare Bio-sciences. We would like to acknowledge the help extended to us by many of our colleagues at GE Healthcare Bio-sciences for fruitful discussions and for direct assistance in the analytical characterisation of purified rHSA. Special thanks go to J. Flensburg, I. Olsson, B. Jäderlund, and J. Shanagar. We would also like to thank Professor J.-C. Janson at CSB for good advice and encouragement. ÄKTAexplorer, UNICORN, Sepharose, Superdex, Capto, PhastGel, SOURCE, Immobiline and IPGphor are products of the GE Healthcare corporation.

\section{REFERENCES}

1. Andersson, L.O.; Lundén, R. (1976) In: Plasma Proteins, Blombäck, B.; Hanson, L.A., eds.; AB KABI, AWE/GEBERS, Bohuslänningen AB: Uddevalla, 31-34.

2. The Green Cross Corp. (Japan): (1993) Recombinant human serum albumin, process for producing the same and pharmaceutical preparation containing the same. European Patent Application, Publication number: 0570916 A2.

3. The Green Cross Corp. (Japan): (1995) Recombinant human serum albumin, process for producing the same and pharmaceutical preparation containing the same. U S Patent 5, 440, 018.

4. Lakusta, H.; Sarkar, B. (1979) Equilibrium studies of Zinc(II) and Cobalt(II) binding to tetrapeptide analogues of the amino terminus of human serum albumin. J. Inorg. Biochem., 11: 303.

5. Sarkar, B.; Wigfield, Y. (1968) Evidence for albumin- $(\mathrm{Cu}(2)$-amino acid ternary complex. Can. J. Biochem., 46: 601.

6. Peters, T.; Blumenstock, F.A. (1967) Copper-binding properties of bovine serum albumin and its amino-terminal peptide fragment. J. Biol. Chem., 242: 1574.

7. Tarelli, E.; Mire-Sluis, A.; Tivnann, H.A.; Bolgiano, B.; Crane, D.T.; Gee, C.; Lemercinier, X.; Athayde, M.L.; Sutcliffe, N.; Corran, P.H.; Rafferty, B. (1998) Recombinant human albumin as a stabilizer for biological materials and for the preparation of international reference reagents. Biologicals, 26: 1045.

8. Valmet, E. (1969) The heterogeneity of human serum albumin. Protides of the Biological fluids, H. Peeters, Ed., Pergamon Press, Oxford. 17: 443.

9. Cohn, E.J.; Strong, L.E.; Hughes, W.L.; Mulford, D.J.; Ashworth, J.N.; Melin, M.; Taylor, H.L. (1946) Preparation and properties of serum and plasma proteins. IV. A system for the separation into fractions of the protein 
and lipoprotein.components of biological tissues and fluids. J. Am. Chem. Soc., 68: 459.

10. Curling, J.M.; Berglöf, J.; Lindquist, L-O.; Eriksson, S. (1977) A chromatographic procedure for the purification of human plasma albumin. Vox Sang, 33: 97.

11. Berglöf, J.H.; Eriksson, S.; Curling, J.M. (1983) Chromatographic preparation and in vitro properties of albumin from human plasma. J. Appl. Biochem., 5: 283.

12. (1989) WHO Expert Committee on Biological Standardisation: 39th Report, Technical Report Series 786, World Health Organisation, Geneva.

13. Lin, J-J.; Meyer, J.D.; Carpenter, J.F.; Manning, M.C. (2000) Stability of human serum albumin during bioprocessing: Denaturation and aggregation during processing of albumin paste. Pharmaceutical Research, 17: 391.

14. Watanabe, H.; Kragh-Hansen, U.; Tanase, S.; Nakajo, K.; Mitarai, M.; Iwao, Y.; Maruyama, T.; Otagiri, M. (2001) Conformational stability and warfarin binding properties of human serum albumin studied by recombinant mutants. Biochemical Journal, 357: 269.

15. Petersen, C.E.; Ha, C.E.; Harohalli, K.; Felix, J.B.; Bhagavan, J.B. (2000) A dynamic model for bilirubin binding to human serum albumin. J. Biol. Chem., 275: 20985. 